\title{
Author Correction: Mosaic nanoparticle display of diverse influenza virus hemagglutinins elicits broad $B$ cell responses
}

Masaru Kanekiyo (D), M. Gordon Joyce iD, Rebecca A. Gillespie, John R. Gallagher (iD, Sarah F. Andrews, Hadi M. Yassine, Adam K. Wheatley (D), Brian E. Fisher, David R. Ambrozak, Adrian Creanga, Kwanyee Leung, Eun Sung Yang, Seyhan Boyoglu-Barnum, Ivelin S. Georgiev, Yaroslav Tsybovsky, Madhu S. Prabhakaran, Hanne Andersen (D, Wing-Pui Kong, Ulrich Baxa, Kathryn L. Zephir, Julie E. Ledgerwood, Richard A. Koup, Peter D. Kwong, Audray K. Harris (D, Adrian B. McDermott, John R. Mascola and Barney S. Graham D

Correction to: Nature Immunology https://doi.org/10.1038/s41590-018-0305-x (2019), published online 11 February 2019.

In the version of this article initially published, the labels ( $50 \AA$ ) above the scale bars in Fig. $1 \mathrm{~b}$ were incorrect. The correct size is $50 \mathrm{~nm}$. The error has been corrected in the HTML and PDF versions of the article.

Published online: 12 April 2019

https://doi.org/10.1038/s41590-019-0395-0

\section{Publisher Correction: Dynamic changes to lipid mediators support transitions among macrophage subtypes during muscle regeneration}

Nikolas Giannakis, Brian E. Sansbury, Andreas Patsalos (D), Tristan T. Hays, Colin O. Riley, Xianlin Han, Matthew Spite (D) and Laszlo Nagy $\mathbb{D}$

Correction to: Nature Immunology https://doi.org/10.1038/s41590-019-0356-7 (2019), published online 1 April 2019.

In the version of this article initially published, two arrows in the far right plot of Fig. $3 \mathrm{c}$ were aimed incorrectly, and the error bars were missing in Fig. 6e, f. In Fig. 3c, the arrow labeled '5-LOX' should be aimed at the plot measuring $\mathrm{LXB}_{4}$, and the arrow labeled 'LTA $4 \mathrm{H}^{\prime}$ should be aimed at the plot measuring $\mathrm{LTB}_{4}$. The errors have been corrected in the HTML and PDF versions of the article. 